\title{
STUDI ANALISIS DAMPAK AKULTURASI BUDAYA TERHADAP SIKAP UKHUWWAH ISLAMIYYAH MAHASISWA DALAM DIMENSI GLOBALISASI
}

\author{
Mohammad Rindu Fajar Islamy ${ }^{1}$, Muhamad Parhan², Jenuri ${ }^{3}$, \\ Dina Mayadiana Suwarma ${ }^{3}$ \\ Universitas Pendidikan Indonesia Bandung Jawa Barat ${ }^{1,2,3,4}$ \\ Email: fajarislam2000@upi.edu,parhan.muhamad@upi.edu, jenuri@upi.edu, \\ dinamayadiana@upi.edu
}

\begin{abstract}
The flow of globalization has had a huge impact on cultural and cultural changes that have developed in modern society. Indonesia is a country that has diversity and differences in ethnicity, customs, culture, and culture so this can certainly be a multidimensional conflict that is not managed properly. One of the solutions offered by the religion of Islam in minimizing this potential is to improve the attitudes and behavior of the ukhuwwah Islamiyyah among Muslims. This research study aims to examine and examine the impact of cultural acculturation on the attitude of ukhuwwah Islamiyyah among university students. The research method used a quantitative approach by applying an analytic descriptive study. Using a random sampling technique, participants took from 43 student respondents from the Faculty of Education. The value measurement technique uses a Likert scale. The variable components of ukhuwwah Islamiyyah are divided into four, namely mutual help, tolerance, friendship, and obligations to fellow Muslims. The results showed that globally the attitude of ukhuwwah Islamiyyah had a good predicate. Students with a cultural background of Bugis get a score of 75\%, then Javanese culture is $72.89 \%$, Malay 77.50\%, Minang 78\%, Sundanese $74.70 \%$, and a combination of Javanese and Sundanese culture is $77.50 \%$. This assessment illustrates that culture has a strategic role in shaping the attitude of ukhuwwah Islamiyyah for university students in the world of modernity.
\end{abstract}

Keywords: Students, Acculturation, Culture, Ukhuwwah Islamiyyah, Globalization.

Dunia pendidikan pada saat ini dihadapkan pada berbagai macam tantangan yang begitu kompleks dan beragam, salah satunya adalah perubahan kondisi dunia menuju arah globalisasi. Globalisasi lahir sebagai kekuatan baru baik dari sisi sosial, politik maupun ekonomi dengan menantang batas-batas wilayah nasional, norma dan perilaku budaya di seluruh dunia (Weldon et al., 2011). Dalam perspektif historis, para intelektual melihat bahwa arus ini berubah menjadi satu transformasi kuat dengan proses yang panjang, walaupun dalam dua dekade ini efeknya betul-betul terasa signifikan. Kekhawatiran begitu dirasakan oleh para intelektual dunia akibat dampak yang ditimbulkannya, serta tentunya mendorong mereka untuk melakukan riset lebih dalam mengenai diskursus ini. Intelektual internasional Rawashdeh melakukan satu riset terkait dampak globalisasi terhadap budaya politik pemuda Arab Saudi (Al-Rawashdeh, 2014). Intelektual China Wing Wah Law telah membuktikan bahwa globalisasi telah menekan pendidikan nilai untuk menyelesaikan kontradiksi yang jelas antara identitas nasional dan persatuan nasional dalam permainan sejarah dan politik China yang terus berubah (Law \& Ho, 2009). Dalam aspek ekonomi, intelektual 


\section{-}

Korea Jai Mah mengungkapkan adanya dampak buruk yang disebabkan arus globalisasi terhadap ketimpangan pendapat ekonomi di Korea (Mah, 2002). Selaras dengan Jai Mah, Jonathan London menyimpulkan dari analisis riset yang diangkatnya bahwa hasil menunjukkan gelombang globalisasi yang berturut-turut telah mempengaruhi tata kelola pendidikan di Vietnam secara berbeda (London, 2010). Di Jamaika, Kinkead-Clark menemukan bukti kuat adanya dampak yang ditimbulkan oleh globalisasi terhadap pendidikan anak (Kinkead-Clark, 2017).

Studi penelitian terhadap perkembangan diskursus globalisasi menjadi topik hangat para intelektual internasional pada saat ini (Needles, 2010; THIVIERGE, 2003; Thompson, 2019; Utsumi, 2006). sebagaimana yang dilakukan oleh Sonia Nieto dalam publikasi jurnal internasional berjudul "diversity, globalization, and education: What Do They Mean for Teachers and Teacher Educations?", studi ini mencoba menggali bagaimana tantangan yang harus dihadapi oleh dunia pendidikan di Amerika Serikat dalam menghadapi keberagaman kultur dan budaya dampak dari arus globalisasi (Nieto, 2013). Hasil studi menemukan bahwa saat ini, Amerika Serikat rupanya dipandang belum siap untuk mempersiapkan guru dalam rangka mengelola keberagaman siswa imigran yang cenderung heterogen dari berbagai negara konflik. Selanjutnya, riset yang dilakukan oleh Keith Watson dimana studinya mencoba membahas dampak globalisasi pada reformasi pendidikan dan kebijakan bahasa bagi masyarakat transisi, transformasi, dan rekonstruksi (Watson, 2001). Studi lain yang dilakukan oleh Martin Albrow dan kawan kawan menyoroti dampak yang diberikan oleh globalisasi bagi wilayah sosiologi. Mereka melihat bahwa proses global melahirkan komunitas-komunitas baru dengan kerangka hubungan sosial yang khas dalam konteks masyarakat global (Albrow et al., 1994).

Dalam dunia akademik diperguruan tinggi, sebagaimana yang dikemukakan oleh Severino Macingambi, beberapa pemikir ternama menilai globalisasi cenderung mengubah system pendidikan dari layanan public menjadi komoditas komersial yang dijual untuk mendapatkan profit yang besar dengan akhir bahwa siswa dari kelas sosial bawah tidak akan mau membelinya (Machingambi, 2014). Selain itu, globalisasi mereduksi nilai dan etos dalam system perguruan tinggi yang pada akhirnya menyebabkan meningkatnya ketidaksetaraan pendidikan dan ketidakharmonisan sosial. Di beberapa negara Eropa seperti Belgia, Kanada, Inggris, dan Amerika Serikat, pendidikan tinggi diperguruan tinggi masih tetap mempertahankan sifat khasnya dengan tetap meninjau peluang yang ditawarkan oleh globalisasi dan internasionalisasi (Tight, 2021). Robert Burner bahkan mengkhawatirkan dampak yang ditimbulkan yaitu kesenjangan yang cukup besar antara apa yang dibutuhkan dunia dan apa yang umumnya dilakukan oleh para praktisi manajemen dalam dunia pendidikan (Bruner \& Iannarelli, 2011). Dalam menghadapi dimensi globalisasi, Lin Goodwin menawarkan konseptual alternatif apa yang seharusnya dimiliki oleh para guru abad sekarang, dimana menurutnya setidaknya guru harus memiliki 
empat dimensi; kurikuler, professional, moral yang bagus, dan kepribadian yang baik (Goodwin, 2020).

Sementara disisi yang lain, diskursus akulturasi budaya menjadi salah satu topik hangat yang sedang diperbincangkan oleh para intelektual baik nasional maupun internasional (Ortin et al., 2018; Zhang et al., 2019). Riset yang dikembangkan oleh Valenzuela dan kawan kawan mencoba mengembangkan strategi model penerapan pendekatan akulturasi bagi terciptanya kesesuaian antara individu dengan lingkungan (Valenzuela \& Rogers, 2018). Akulturasi memiliki dua sisi yang saling berpotensi satu sama lain, dapat berkontribusi positif namun dapat pula berdampak negative. Beberapa negara melakukan penerapan kebijakan yang ketat terhadap para imigran yang menetap dinegaranya karena dikhawatirkan memberikan dampak negative dari proses akulturasi budaya yang dibawa oleh mereka ke tengah-tengah masyarakat. sebagai contoh, studi penelitian yang dilakukan oleh Larrañaga dan kawan-kawan untuk menganalisis pengaruh identitas etnis terhadap kelompok tradisional Bosque (penduduk asli Spanyol) dan terhadap kelompok pendatang baru (Larrañaga et al., 2016). Selanjutnya penelitian yang dilakukan oleh Stefanidi dan kawan-kawan bertujuan untuk untuk mengetahui akulturasi, kesejahteraan psikologis, dan penyesuaian sekolah remaja Pontian dari bekas Uni Soviet (FSU-Pontians), yang merupakan imigran dari diaspora yang tinggal di Yunani, dibandingkan dengan kelompok imigran asal Albania (Motti-Stefanidi et al., 2008). Secara umum, para peneliti percaya bahwa akulturasi memberikan dampak terhadap tingkah laku maupun pemikiran yang berkembang dimasyarakat (Archuleta, 2012; Cort, 2010; du Preez \& Govender, 2020; Johnson, 1996; Levinson \& Rodebaugh, 2013; Makarova et al., 2019; Ortin et al., 2018; Reynolds et al., 2012).

Indonesia merupakan sebuah negara yang mempunyai keberagamaan baik suku, budaya, agama, bahasa, maupun adat istiadat. Hal ini tentunya berdampak terhadap adanya proses akulturasi dan asimilasi yang berkontribusi besar terhadap meningkatkan keberagamaan dan keunikan yang ada di negara ini. Blended Culture atau penggabungan budaya merupakan sesuai yang fitrah dan lumrah terlebih arus perubahan saat ini yang begitu cepat disebabkan perkembangan teknologi dan arus globalisasi. Pada tataran pelaksanaannya, masyarakat berupaya menerima hal-hal baru yang positif yang dilandaskan kepada kerangka berpikir mereka. Tidak hanya aspek budaya, akulturasi pun dapat tertular kepada proses penyebaran agama. Seperti Islam, agama ini dipandang oleh para peneliti masuk ke Indonesia melalui empat pola; pertama, dibawa langsung dari Arab, kedua, diperkenalkan oleh para guru dan pendakwah professional, ketiga, dibawa oleh para penguasa, dan keempat yaitu oleh para penyebar professional Islam. Menurut Budiwibowo, budaya kearifan lokal dapat berfungsi menjadi alat dalam membangun pendidikan karakter bangsa dengan cara menanamkan masyarakat pada nilai-nilai luhur bersifat universal (Budiwibowo, 2016). 


\section{8}

Al-Quran merupakan petunjuk jalan dan pedoman hidup yang harus diaktualisasikan dalam kehidupan bermasyarakat (Al-Qardhawi, 1996, 2007). Penanaman nilai-nilai spritualitas telah difondasikan oleh Rosulullah saw kepada para sahabatnya sebagai bagian upaya dalam rangka mewujudkan agama Islam yang rahmatan lil alamin (As-Shalabi, 2008; Ghadhban, 1992; Rawwas, 1988; Rindu et al., 2020). Salah satu ulama kontemporer syeikh Muhammad Abdullah Ad-Duwais dalam karyanya berjudul Fiqh Al-Wifaq menuturkan bahwa setidaknya ada beberapa alasan kuat yang menjadi landasan agama memerintahkan umatnya untuk memperkokoh rasa persaudaraan dan persatuan diantaranya; pertama, Al-Quran memerintahkan mempererat rasa persatuan sebagaimana dalam QS. Ali Imran (3) ayat 102-103 serta QS. Hud (11) ayat 118119; kedua, Visi global di utusnya para Nabi, hal ini ditegaskan oleh Imam AlBaghawi bahwa Allah mengutus para Nabi semuanya dalam rangka menegakkan agama dan persaudaraan dalam barisan jamaah serta melarang tindakan perpecahan; ketiga, Dalil Argumentatif berasal dari As-Sunnah sebagaimana yang diriwayatkan oleh Abu Hurairah serta Al-Harits Al-Asy'ari; keempat, teladan yang telah ditradisikan oleh para sahabat; kelima, persatuan dan persaudaraan merupakan karakteristik Ahlu Sunnah Wal Jamaah (Al-Dirasah, 1434). Penelitian ini bertujuan untuk mencoba membuktikan adanya hubungan yang dinamis antara budaya dengan sikap ukhuwwah islamiyyah dikalangan masyarakat pada umumnya, serta mahasiswa pada khususnya. Ikatan persaudaraan merupakan komponen dasar yang menjadi perhatian serius inti ajaran agama sehingga perlu adanya upaya-upaya preventif untuk memperkuat profil tersebut. Dari sedikit ulasan yang dikemukakan oleh Syeikh Ad-Duwais, riset ini berupaya memberikan kontribusi positif dalam rangka melakukan potret awal sejauh mana sikap ukhuwwah islamiyyah terbangun dikalangan mahasiswa diperguruan tinggi, sehingga diharapkan dengan adanya arus globalisasi serta dampak yang ditimbulkan oleh akulturasi budaya tidak berkontribusi negative dalam rangka menjaga persatuan dalam masyarakat di Indonesia.

\section{Metodologi Penelitian}

\section{Jenis dan Pendekatan Penelitian}

Jenis penelitian yang digunakan dalam penelitian ini adalah penelitian kuantitatif. Menurut Suharsimi Arikunto, penelitian kuantitatif adalah "suatu proses penelitian untuk menemukan pengetahuan yang menggunakan data berupa angka sebagai alat untuk menemukan keterangan mengenai apa yang ingin diketahui". Sedangkan pendekatannya menggunakan deskriptif. Nazir menjelaskan pendekatan deskriptif adalah suatu pendekatan dalam meneliti status kelompok manusia, suatu subjek, suatu set kondisi, suatu sistem pemikiran atau pun kelas peristiwa pada masa sekarang. Tujuan dari penelitian deskriptif ini adalah membuat deskripsi, gambaran atau lukisan secara sistematis serta hubungan antar fenomena yang diselidiki. 


\section{Tempat dan Waktu Penelitian}

Tempat penelitian ini adalah Mahasiswa Fakultas Ilmu Pendidikan (selanjutnya disingkat FIP) Universitas Pendidikan Indonesia. Alasan peneliti mengadakan penelitian di tempat tersebut karena Mahasiswa FIP berasal dari berbagai macam asal daerah, suku, keyakinan beragama yang berbeda-beda. Sehingga perbedaanperbedaan tersebut dapat diamati, interaksi mahasiswa dalam hal menerapkan sikap ukhuwah Islamiah, karena prinsip persaudaraan dalam Islam adalah menebarkan kasih sayang, saling menghormati, saling kerjasama dengan tidak membeda-bedakan golongan. Waktu penelitian dilaksanakan pada bulan Februari 2020 .

\section{Populasi, Sampel, dan Teknik Sampling}

Populasi adalah wilayah generalisasi yang terdiri atas obyek atau subyek yang mempunyai kualitas dan karakteristik tertentu yang ditetapkan oleh peneliti untuk dipelajari dan kemudian ditarik kesimpulannya. Berdasarkan pernyataan tersebut, dalam penelitian ini yang menjadi populasi adalah Masiswa Fakultas Ilmu Pendidikan Universitas Pendidikan Indonesia. Suharsimi Arikunto memberikan ketentuan "apabila jumlah populasi penelitian kurang dari 100 sebaiknya diambil semua sehingga penelitian ini menjadi penelitian populasi". Bila populasi besar, dan peneliti tidak mungkin mempelajari semua yang ada pada populasi, maka peneliti dapat menggunakan sampel yang diambil dari populasi itu. Apa yang dipelajari dari sampel itu, kesimpulannya akan dapat diberlakukan untuk populasi. Untuk itu sampel yang diambil dari populasi harus betul-betul representatif (mewakili). Teknik pengambilan sampel yang digunakan dalam penelitian ini adalah teknik random sampling, yaitu metode pengambilan sampel dengan memberikan peluang yang sama kepada setiap individu untuk dijadikan sebagai sampel penelitian. Random Sampling digunakan sebab dengan random dapat memberikan peluang yang sama kepada semua populasi, sehingga dipandang sampel lebih representatif.

\section{Variabel dan Indikator Penelitian}

Variabel penelitian adalah segala sesuatu yang berbentuk apa saja yang ditetapkan oleh peneliti untuk dipelajari sehingga diperoleh informasi tentang hal tersebut, kemudian ditarik kesimpulannya. Sedangkan indikator merupakan penjabaran yang lebih spesifik berkaitan dengan variabel yang telah ditentukan. Dalam penelitian ini terdapat dua variabel penelitian, yaitu:

1. Variabel Y, yaitu sikap ukhuwah Islamiah mahasiswa, dengan indikator:

a) Tolong-menolong

b) Toleransi

c) Menegakkan Silaturahim

d) Kewajiban Sesama Muslim. 
2. Variabel X, yaitu Latar belakang budaya mahasiswa FIP

\section{Teknik Pengumpulan Data}

Pengumpulan data melalui kumpulan pertanyaan yang disusun secara sistematis kemudian dikirim kepada responden untuk diisi. Tujuan penyebaran angket yaitu mencari informasi yang lengkap mengenai suatu masalah dari responden tanpa merasa khawatir bila responden memberikan jawaban yang tidak sesuai dengan kenyataan dalam pengisian daftar pertanyaan.

Ditinjau dari segi cara menjawabnya, kuesioner dibedakan menjadi dua:

a) Kuesioner tertutup adalah "kuesioner yang disusun dengan menyediakan pilihan jawaban lengkap, sehingga pengisi hanya tinggal memberi tanda pada jawaban yang dipilih".

b) Kuesioner terbuka adalah kuesioner yang disusun sedemikian rupa sehingga pengisi bebas mengemukakan pendapatnya".

Dalam penelitian ini kuesioner yang digunakan oleh peneliti sebagai pengumpulan data adalah kuesinoner tertutup. Metode ini digunakan untuk memperoleh data mengenai sikap ukhuwah Islamiah mahasiswa FIP. Selanjutnya pengukuran nilai menggunakan skala likert. Skala Likert merupakan metode pengukuran yang digunakan untuk mengukur sikap, pendapat dan persepsi seseorang atau kelompok orang tentang fenomena sosial. Adapun alternatif jawaban terdiri dari empat pilihan jawaban yaitu selalu (SL), sering (SR), kadangkadang (KD), dan tidak pernah (TP). Untuk memudahkan pengelolaan data statistiknya, maka dari setiap item soal positif diberika skor sebagai berikut:
a. Untuk alternatif jawaban "SL" diberi skor 4
b. Untuk alternatif jawaban "SR" diberi skor 3
c. Untuk alternatif jawaban "KD" diberi skor 2
d. Untuk alternatif jawaban "TP" diberi skor 1 .

Sedangkan untuk item soal negatif maka penskoran dilakukan sebaliknya, yaitu skor untuk alternatif jawaban "SL-TP" diberi skor 1-4.
a. Untuk alternatif jawaban "SL" diberi skor 1
b. Untuk alternatif jawaban "SR" diberi skor 2
c. Untuk alternatif jawaban "KD" diberi skor 3
d. Untuk alternatif jawaban "TP" diberi skor 4

Teknik Analisis Data 
Dalam penelitian kuantitatif, analisis data merupakan kegiatan setelah data dari seluruh responden atau sumber data lain terkumpul. Kegiatan dalam analisis data adalah mengelompokkan data berdasarkan variabel dan jenis responden, menabulasi data berdasarkan variabel dari seluruh responden, menyajikan data tiap variabel yang diteliti, melakukan perhitungan untuk menguji hipotesis yang telah diajukan. Untuk menganalisa data yang terkumpul, peneliti menggunakan teknik analisis statistik deskriptif. Analisis statistik deskriptif adalah analisis statistik yang mempunyai tugas mengorganisasi dan menganalisis data angka, agar dapat memberikan gambaran secara teratur, ringkas dan jelas, mengenai suatu gejala, peristiwa, atau keadaan, sehingga dapat ditarik pengertian atau makna tertentu. Tujuan dilakukan analisis deskriptif dengan teknik statistik adalah untuk meringkas data agar menjadi lebih mudah dilihat dan dimengerti.

\section{Hasil Penelitian}

Berdasarkan hasil penelitian, didapati responden yang berkontribusi dalam penelitian ini berjumlah 43 responden. Berikut data responden berdasarkan jenis kelamin, jurusan, dan asal suku.

Tabel 4.1.1

\section{Responden Penelitian Berdasarkan Jenis Kelamin}

\begin{tabular}{ccc}
\hline No & Jenis Kelamin & Jumlah \\
\hline 1 & $\mathrm{P}$ & 32 \\
\hline 2 & $\mathrm{~L}$ & 11 \\
\hline & Total & $\mathbf{4 3}$
\end{tabular}

Responden penelitian ini jika dilihat berdasarkan jenis kelamin didapatkan data bahwa jumlah responden laki-laki adalah 11 responden dan perempuan 32 responden. Jika dirasiokan maka perbandingannya adalah $1: 3$.

Tabel 4.1.2

Responden Penelitian Berdasarkan Jurusan

\begin{tabular}{clc}
\hline No & \multicolumn{1}{c}{ Jurusan } & Jumlah \\
\hline 1 & Administrasi Pendidikan & 1 \\
\hline 2 & Bimbingan dan Konseling & 6 \\
\hline 3 & Pendidikan Guru Sekolah Dasar (PGSD) & 6 \\
\hline 4 & Pendidikan Khusus & 7 \\
\hline 5 & Pendidikan Masyarakat & 4 \\
\hline 6 & Perpustakaan dan Sains Informasi (Perpusinfo) & 3 \\
\hline 7 & Teknologi Pendidikan & 16 \\
\hline & Total & $\mathbf{4 3}$ \\
\hline
\end{tabular}


Berdasarkan jurusan yang ada di Fakultas Ilmu Pendidikan (FIP), terdapat 7 jurusan yang berkontribusi dalam penelitian ini, diantaranya adalah Administrasi Pendidikan 1 orang; Bimbingan dan Konseling 6 orang; PGSD 6 orang; Pendidikan Khusus 7 orang; Pendidikan Masyarakat 4 orang; Perpusinfo 3 orang; dan Teknologi Pendidikan 16 orang.

Tabel 4.1.3

Responden Penelitian Berdasarkan Asal Suku

\begin{tabular}{clc}
\hline No & Jurusan & Jumlah \\
\hline 1 & Sunda & 27 \\
\hline 2 & Jawa & 9 \\
\hline 3 & Minang & 2 \\
\hline 4 & Melayu & 2 \\
\hline 5 & Bugis & 1 \\
\hline 6 & Campuran (Sunda dan Jawa) & 2 \\
\hline & Total & $\mathbf{4 3}$
\end{tabular}

Berdasarkan asal suku mahasiswa FIP UPI, terdapat 6 asal suku dari para responden, diantaranya adalah Suku Sunda 27 orang; Jawa 9 orang; Minang 2 orang; Melayu 2 orang; Bugis 1 orang; dan Campuran (Sunda dan Jawa) 2 orang.

Para responden dalam penelitian ini diberikan 25 item pernyataan dengan 4 pilihan jawaban dengan menggunakan skala likert. Pilihan jawabannya adalah Tidak Pernah (TP), Kadang-kadang (KK). Sering (SR), dan Selalu (SL). Setiap pilihan jawaban memiliki poin tersendiri sebagaimana yang telah dijelaskan di bagian sebelumnya. Skor minimal dari keseluruhan item penelitian adalah 25 dan skor maksimal 100. Berikut raihan skor responden penelitian.

Tabel 4.1.4

Raihan Skor Responden Penelitian

\begin{tabular}{ccc}
\hline No & Responden & Skor \\
\hline 1 & NW & 98 \\
\hline 2 & AKA & 90 \\
\hline 3 & SFA & 89 \\
\hline 4 & TS & 89 \\
\hline 5 & N & 87 \\
\hline 6 & RS & 85 \\
\hline 7 & FR & 82 \\
\hline 8 & A & 81 \\
\hline
\end{tabular}




\begin{tabular}{|c|c|c|}
\hline 9 & SA & 80 \\
\hline 10 & $\mathrm{JF}$ & 80 \\
\hline 11 & AT & 79 \\
\hline 12 & $\mathrm{AU}$ & 79 \\
\hline 13 & FA & 78 \\
\hline 14 & $\mathrm{M}$ & 78 \\
\hline 15 & SDK & 78 \\
\hline 16 & $\mathrm{YH}$ & 77 \\
\hline 17 & SR & 75 \\
\hline 18 & FK & 75 \\
\hline 19 & $\mathrm{MC}$ & 75 \\
\hline 20 & FY & 75 \\
\hline 21 & $\mathrm{~N}$ & 74 \\
\hline 22 & DMD & 74 \\
\hline 23 & LK & 73 \\
\hline 24 & FAZ & 72 \\
\hline 25 & MRY & 72 \\
\hline 26 & $\mathrm{R}$ & 72 \\
\hline 27 & DS & 71 \\
\hline 28 & SNR & 71 \\
\hline 29 & $\mathrm{AF}$ & 71 \\
\hline 30 & $\mathrm{AF}$ & 71 \\
\hline 31 & $\mathrm{R}$ & 70 \\
\hline 32 & $Q$ & 69 \\
\hline 33 & IT & 69 \\
\hline 34 & NFA & 69 \\
\hline 35 & $\mathrm{NF}$ & 68 \\
\hline 36 & NFA & 68 \\
\hline 37 & $\mathrm{~F}$ & 66 \\
\hline 38 & $\mathrm{RF}$ & 65 \\
\hline 39 & FR & 64 \\
\hline 40 & AWL & 64 \\
\hline 41 & $\mathrm{JM}$ & 63 \\
\hline 42 & IFS & 63 \\
\hline 43 & $\mathrm{EF}$ & 61 \\
\hline
\end{tabular}


Dari raihan skor para responden diatas, dapat diketahui bahwa para mahasiswa FIP UPI memiliki skor rata-rata 75, artinya mahasiswa FIP UPI memiliki sikap ukhuwah islamiyah yang baik. Dibawah ini kategorisasi sikap ukhuwah islamiyah mahasiswa FIP UPI.

Tabel 4.1.5

Kategorisasi Sikap Ukhuwah Islamiyah

\begin{tabular}{ccc}
\hline No & Kategori & Rentang \\
\hline $\mathbf{1}$ & Sangat Baik & $76-100$ \\
\hline $\mathbf{2}$ & Baik & $51-75$ \\
\hline $\mathbf{3}$ & Cukup & $26-50$ \\
\hline $\mathbf{4}$ & Kurang & $1-25$ \\
\hline
\end{tabular}

\section{Diskusi dan Analisis}

Pada hasil penelitian diatas, responden yang merupakan mahasiswa Fakultas Ilmu Pendidikan (FIP) Universitas Pendidikan Indonesia (UPI) diketahui mendapatkan skor rata-rata 75 pada sikap ukhuwah islamiyah. Skor tersebut termasuk pada kategori baik dalam mencerminkan sikap ukhuwah islamiyah. Sikap ukhuwah islamiyah terdiri dari 4 indikator yaitu tolong menolong, toleransi, silaturahim, dan kewajiban sesama muslim. Berikut grafik sikap ukhuwah islamiyah mahasiswa FIP UPI.

\section{Grafik 4.2.1}

\section{Profil Sikap Ukhuwah Mahasiswa FIP UPI}

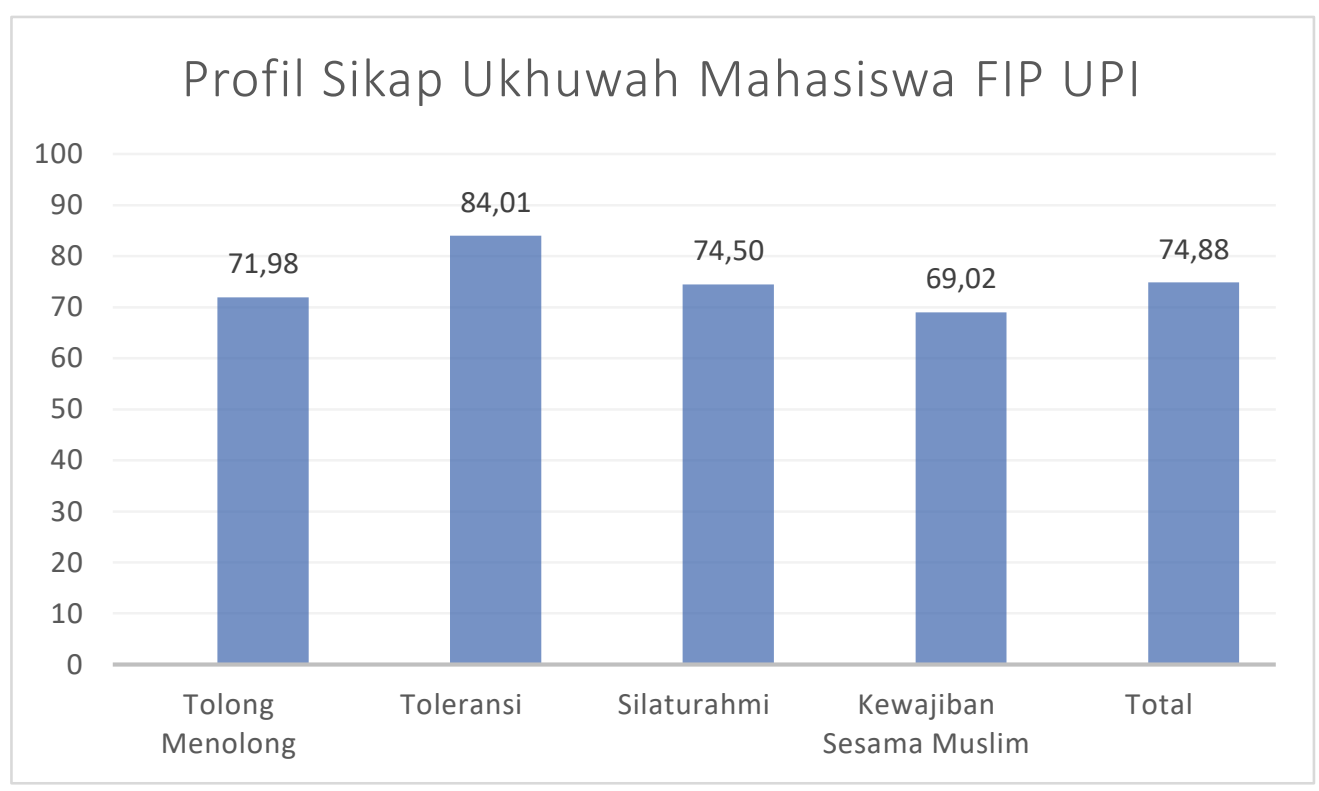




\section{.}

Pada indikator tolong menolong, hasil penelitian menunjukan skor 71,98 yang termasuk kategori baik dalam sikap ukhuwah islamiyah. Mahasiswa FIP UPI dapat dikatakan mampu bersikap baik dengan saling membantu, memberi, dan memperbaiki temannya sebagai bentuk sikap tolong menolong yang merupakan bagian dari sikap ukhuwah islamiyah. Berdasarkan grafik diatas, indikator toleransi mahasiswa FIP UPI berada pada skor tertinggi dibandingkan dengan indikator yang lain yaitu 84,01. Skor tersebut termasuk kategori sangat baik. Sehingga mahasiswa FIP UPI dapat disimpulkan sangat baik dalam menghargai kemampuan orang lain, menghormati orang lain, dan bersikap tenggang rasa sebagai bentuk implementasi sikap ukhuwah islamiyah. Pada indikator silaturahim didapatkan skor 74,5 yang termasuk kategori baik. Hal ini menunjukan bahwa mahasiswa FIP UPI mampu dengan baik mengimplementasikan silaturahim dengan orang lain melalui berkunjung ke rumah guru/dosen, saling menyapa, memaafkan, dan saling memperbaiki hubungan agar menjadi baik kembali. Indikator kewajiban sesama muslim sebagai indokator terakhir dari sikap ukhuwah islamiyah menunjukan skor 69.02 yang termasuk kategori baik. Dalam hal ini mahasiswa FIP UPI telah mampu dengan baik melaksanakan kewajibannya sebagai seorang muslim dengan menjawab salam, memberi nasihat, menjawab doa orang yang bersin, mengunjungi orang sakit, dan ikut serta dalam mengurus hak-hak orang yang wafat.

Dari hasil penelitian, ditemukan bahwa secara umum mahasiswa FIP UPI memiliki sikap ukhuwah Islamiyah baik, yaitu sikap tolong menolong, toleransi, silaturahuim, dan kewajiban sesama muslim. Tentunya, terdapat faktor-faktor penyebab adanya sikap-sikap tersebut dalam pribadi mahasiswa FIP UPI ditinjau dari kultur akademik dan pembiasaan keseharian FIP UPI. Pertama, mahasiswa FIP UPI dituntut untuk memiliki rasa peduli yang tinggi terhadap orang lain, sebagai dasar dan modal penting di dunia pendidikan. Mahasiswa FIP UPI diorientasikan untuk menjadi role model. Oleh karenanya, mahasiswa FIP UPI memiliki sikap tolong-menolong yang baik. Mahasiswa FIP UPI memiliki kultur "empati dan peka terhadap keadaan orang lain". Kedua, menjadi guru atau pendidik harus memiliki prinsip "education for all” yang menegaskan bahwa tidak ada diskriminasi. Inilah yang berpengaruh terhadap adanya sikap "toleransi" pada diri mahasiswa FIP UPI, menegaskan perlunya mahasiswa FIP UPI mendidik para siswanya kelak tanpa memilihh-milih. Ketiga, faktor penyebab lainnya terhadap adanya sikap-sikap ukhuwah islamiah adalah bahwa mahasiswa FIP UPI diorientasikan untuk memiliki keterampilan berkomunikasi dengan baik. Menjadi guru adalah menjadi komunikator yang baik. Karenanya, sikap "silaturahim" menjadi budaya para mahasiswa FIP UPI sebagai sarana pengembangan keterampilan berkomunikasi. Keempat, faktor adanya sikap memenuhi hak sesama muslim merupakan budaya mahasiswa FIP UPI yang dididik untuk melaksanakan kewajiban-kewajiban dengan baik. Jika dirinci lebih jauh mengenai profil sikap ukhuwah mahasiswa, latar belakang budaya perlu diperhatikan 
sebagai bentuk keragaman bangsa Indonesia. Oleh karena itu, penelitian ini juga mencari profil sikap ukhuwah islamiyah mahasiswa FIP UPI berdasarkan latar belakang budaya khususnya asal suku mahasiswa. Berikut grafik sikap ukhuwah islamiyah mahasiswa berdasarkan latar belakang budaya.

\section{Grafik 4.2.2}

\section{Profil Sikap Ukhuwah Mahasiswa FIP UPI Berdasarkan Latar Belakang Budaya}

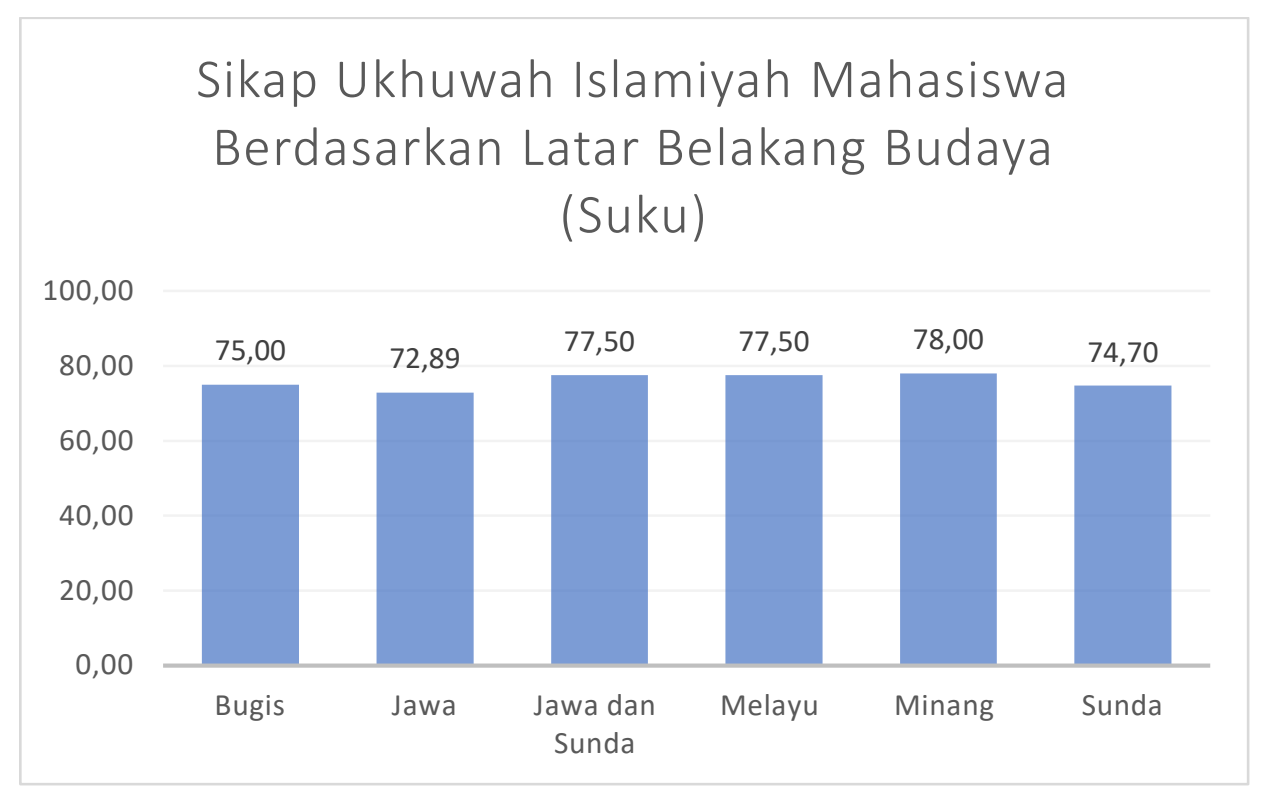

Responden yang berasal dari suku bugis diketahui mendapat skor 75,00. Skor tersebut menunjukan bahwa mahasiswa yang berasal dari suku bugis memiliki sikap ukhuwah islamiyah yang baik. Jika dilihat dari filosofis orang Bugis, terdapat beberapa hal yang sangat berkaitan dengan implementasi sikap ukhuwah islamiyah. Diantaranya terdapat prinsip sipakatau (saling menghormati), sipakainge (saling mengingatkan), sipakalebbi (saling mendukung), dan siri' na pacce (malu berbuat jahat, malu tidak menolong, dan perasaan sedih ketika melihat hal buruk terjadi pada orang lain).

Sementara responden yang berasal dari suku Jawa diketahui mendapatkan skor 72,89. Skor tersebut menunjukan bahwa mahasiswa yang berasal dari suku Jawa memiliki sikap ukhuwah islamiyah yang baik. Dalam suku Jawa, terdapat tradisi budaya yang menunjukan sikap-sikap ukhuwah islamiyah diantaranya tradisi sungkeman yang mengajarkan saling memaafkan satu sama lain, upacara Sekaten yang mengajarkan berbagi dengan orang lain, dan berbagai macam upacara yang menunjukan rasa syukur dan saling tolong menolong antar masyarakat. 
Mahasiswa yang berasal dari suku Melayu mendapatkan skor 77,5 yang berarti mereka memiliki sikap ukhuwah islamiyah yang sangat baik. Hal ini dapat ditunjukan dari berbagai macam tradisi Melayu yang memiliki makna sama dengan ukhuwah islamiyah. Diantara tradisinya yaitu Merisik yang termasuk tradisi pernikahan dalam rangka menyambung tali silaturahim dengan orang lain, tradisi Tepung Tawar yang menunjukan sikap menghormati keberhasilan orang lain, dan upacara Menetau Tanah yang membutuhkan kerjasama atau gotong royong masyarakat dalam membuka lahan pertanian.

Responden dari Suku Minang yang berasal dari Sumatera Barat mendapatkan skor 78,00 . Skor tersebut menunjukan bahwa mahasiswa yang berasal dari suku Minang memiliki sikap ukhuwah islamiyah yang sangat baik. Pencapaian tersebut dapat dilihat dari implementasi berbagai tradisi Minang yang menunjukan sikap ukhuwah islamiyah diantaranya tradisi Balimau yang dilaksanakan dalam menyambut bulan Ramadan sehingga masyarakat saling memaafkan satu sama lain, Makan Bajamba yang menunjukan sikap kebersamaan dan saling berbagi makanan, dan upacara Batagak Kudo-Kudo yang mengundang masyarakat kampung agar membantu dalam membangun tempat tinggal.

Mahasiswa yang berasal dari suku Sunda dalam penelitian ini mendapat skor 74,70 yang berarti mahasiswa yang berasal dari suku Sunda memiliki sikap ukhuwah islamiyah yang baik. Hal itu ditunjukan melalui budaya Sunda yang kental akan kebersamaan dan dekat dengan alam. Filosofi Sunda juga sangat kental akan kebersamaannya yaitu ada istilah silih asah, silih asuh, silih asih yang mencerminkan sikap saling membantu satu sama lain dengan landasan kasih sayang dan rasa saling memiliki. Selain itu ada tradisi Munjung/Ngunjung yang mengajarkan rasa hormat terhadap orang yang dianggap berjasa pada masyarakat dan tradisi bubur Asyura serta Seren Taun yang memerlukan kerjasama antar masyarakat serta sikap saling berbagi satu sama lain.

Mahasiswa yang memiliki asal suku campuran Sunda dan Jawa mendapatkan skor 77,50 yang berarti mereka memiliki sikap ukhuwah islamiyah yang sangat baik. Hal itu dapat diperkirakan karena mereka mendapatkan banyak wawasan dan perbandingan tradisi yang ada di Suku Jawa dan Sunda.

\section{Kesimpulan}

Berdasarkan hasil penelitian terhadap mahasiswa Fakultas Ilmu Pendidikan (FIP) Universitas Pendidikan Indonesia (UPI), profil sikap ukhuwah islamiyah mereka berada pada kategori baik. Hal ini berlaku untuk empat indikator dari sikap ukhuwah islamiyah yaitu tolong menolong, toleransi, menjaga silaturahmi, dan melaksanakan kewajiban sebagai muslim. Sementara jika dilihat dari latar belakang budaya dalam hal ini asal suku, maka mahasiswa yang berasal dari Suku Minang, Melayu, dan Campuran Jawa-Sunda memiliki sikap ukhuwah islamiyah 
sangat baik. Sedangkan mahasiswa yang berasal dari suku Sunda, Jawa, dan Bugis memiliki sikap ukhuwah islamiyah yang baik.

\section{Rekomendasi}

Hasil penelitian ini menunjukan bahwa mahasiswa sebagai individu terpelajar memiliki sikap ukhuwah islamiyah yang baik. Hal ini menunjukan bahwa mahasiswa mampu untuk bersikap baik dalam tolong menolong, toleransi, menjaga silaturahmi, dan melaksanakan kewajiban sebagai muslim. Fenomena ini tentunya perlu dijaga dan dikembangkan melalui berbagai kegiatan akademik maupun non-akademik yang diselenggarakan oleh Himpunan di setiap jurusan, pimpinan jurusan dan Fakultas Ilmu Pendidikan umumnya. Kegiatan-kegiatan positif juga perlu diintergrasikan sebagai implementasi dari ilmu yang diajarkan kepada mahasiswa di kelas. Sehingga pada akhirnya, mahasiswa mampu dengan optimal menunjukan sikap ukhuwah islamiyah yang akan menjadi karakter bagi dirinya sendiri dan bermanfaat bagi orang lain. 


\section{DAFTAR PUSTAKA}

Al-Dirasah, M. A.-B. wa. (1434). Fiqh Al-Wafāq.

Al-Qardhawi, Y. (1996). Al-Ijtihād F̄̄ As-Syarīah Al-Islāmiyyah. Cairo: Dar AlQalam.

Al-Qardhawi, Y. (2007). Ushūl Al-'Amal Al-Khairī F̄̄ Al-Islām F̄̄ Dhaui AnNushūsh Wa Al-Maqāsid As-Syarī'ah. Cairo: Dar As-Syuruq.

Al-Rawashdeh, M. S. (2014). The Impact of Globalization on the Political Culture of the Arab Youths. Journal of Middle Eastern and Islamic Studies (in Asia), 8(4), 81-120. https://doi.org/10.1080/19370679.2014.12023250

Albrow, M., Eade, J., Washbourne, N., \& Durrschmidt, J. (1994). The Impact of Globalization on Sociological Concepts: Community, Culture and Milieu. Innovation: The European Journal of Social Science Research, 7(4), 371389. https://doi.org/10.1080/13511610.1994.9968418

Archuleta, A. J. (2012). Hispanic Acculturation Index: Advancing Measurement in Acculturation. Journal of Human Behavior in the Social Environment, 22(3), 297-318. https://doi.org/10.1080/10911359.2012.655593

As-Shalabi, A. M. (2008). As-Sirah An-Nabiwiyyah Ard Waqa'i Wa Tahlil Ahdats (p. 934). Dar Al-Ma'rifah.

Bruner, R. F., \& Iannarelli, J. (2011). Globalization of Management Education. Journal of Teaching in International Business, 22(4), 232-242. https://doi.org/10.1080/08975930.2011.653908

Budiwibowo, S. (2016). Membangun Pendidikan Karakter Generasi Muda Melalui Budaya Kearifan Lokal Di Era Global. Premiere Educandum: Jurnal Pendidikan Dasar Dan Pembelajaran, 3(01), 39-49. https://doi.org/10.25273/pe.v3i01.57

Cort, D. A. (2010). What happened to familial acculturation? Ethnic and Racial Studies, 33(2), 313-335. https://doi.org/10.1080/01419870903100161

du Preez, E. A., \& Govender, L. K. (2020). Travelling to the Motherland: relating acculturation to diaspora tourism experiences. Anatolia, 31(2), 197-210. https://doi.org/10.1080/13032917.2020.1747220

Ghadhban, M. M. (1992). Fiqh As-Sirah An-Nabawiyyah (p. 752). Jami'ah Ummur Qura.

Goodwin, A. L. (2020). Globalization, Global Mindsets and Teacher Education. Action in Teacher Education, 42(1), 6-18. https://doi.org/10.1080/01626620.2019.1700848

Johnson, M. A. (1996). Latinas and television in the United States: Relationships among genre identification, acculturation, and acculturation stress. Howard Journal of Communications, 7(4), 289-313. 
https://doi.org/10.1080/10646179609361733

Kinkead-Clark, Z. (2017). Early childhood care and education in Jamaica. Stakeholders' perceptions of global influences on a local space. Early Child Development and Care, 187(10), 1484-1495. https://doi.org/10.1080/03004430.2017.1319825

Larrañaga, N., Garcia, I., Azurmendi, M. J., \& Bourhis, R. (2016). Identity and acculturation: interethnic relations in the Basque Autonomous Community. Journal of Multilingual and Multicultural Development, 37(2), 131-149. https://doi.org/10.1080/01434632.2015.1044996

Law, W. W., \& Ho, W. C. (2009). Globalization, values education, and school music education in China. Journal of Curriculum Studies, 41(4), 501-520. https://doi.org/10.1080/00220270802372329

Levinson, C. A., \& Rodebaugh, T. L. (2013). Anxiety, self-discrepancy, and regulatory focus theory: Acculturation matters. Anxiety, Stress and Coping, 26(2), 171-186. https://doi.org/10.1080/10615806.2012.659728

London, J. D. (2010). Globalization and the governance of education in Viet Nam. Asia Pacific Journal of Education, 30(4), 361-379. https://doi.org/10.1080/02188791.2010.520202

Machingambi, S. (2014). The Impact of Globalisation on Higher Education: A Marxist Critique. Journal of Sociology and Social Anthropology, 5(2), 207215. https://doi.org/10.1080/09766634.2014.11885625

Mah, J. S. (2002). The impact of globalization on income distribution: the Korean experience. Applied Economics Letters, 9(15), 1007-1009. https://doi.org/10.1080/13504850210149124

Makarova, E., 't Gilde, J., \& Birman, D. (2019). Teachers as risk and resource factors in minority students' school adjustment: an integrative review of qualitative research on acculturation. Intercultural Education, 30(5), 448477. https://doi.org/10.1080/14675986.2019.1586212

Motti-Stefanidi, F., Pavlopoulos, V., Obradovic, J., \& Masten, A. S. (2008). Acculturation and adaptation of immigrant adolescents in Greek urban schools. International Journal of Psychology, 43(1), 45-58. https://doi.org/10.1080/00207590701804412

Needles, B. E. (2010). Accounting education: The impact of globalization. Accounting Education, 19(6), 601-605. https://doi.org/10.1080/09639284.2010.501578

Nieto, S. (2013). Diversity, Globalization, and Education: What Do They Mean for Teachers and Teacher Educators? Kappa Delta Pi Record, 49(3), 105107. https://doi.org/10.1080/00228958.2013.819183

Ortin, A., Miranda, R., Polanco-Roman, L., \& Shaffer, D. (2018). Parent- 
Adolescent Acculturation Gap and Suicidal Ideation among Adolescents from an Emergency Department. Archives of Suicide Research, 22(4), 529541. https://doi.org/10.1080/13811118.2017.1372828

Rawwas, M. (1988). Dirasah Tahliliyyah Li Syahshiyati Ar-Rasul Muhammad (pp. 1-303). Dar An-Nafais.

Reynolds, A. L., Sodano, S. M., Ecklund, T. R., \& Guyker, W. (2012). Dimensions of acculturation in native American College Students. Measurement and Evaluation in Counseling and Development, 45(2), 101112. https://doi.org/10.1177/0748175611428330

Rindu, M., Islamy, F., Supriadi, U., Wijaya, R., Rojak, A., Romli, U., Anwar, S., Parhan, M., Indonesia, U. P., \& Bandung, K. (2020). Tanfidz Ta'lim AsSyahsyiyyah Dirasah Tahliliyyah Fi Ma'had Al-Inayah Bandung. Lentera Pendidikan, 23(2), 343-356.

THIVIERGE, G.-R. (2003). Globalization and Catholic Higher Education: A Dialogue for Harnessing the Impact of Globalization. Higher Education in Europe, 28(1), 79-82. https://doi.org/10.1080/0379772032000110152

Thompson, M. C. (2019). the Impact of Globalization on Saudi Male Millennials' Identity Narratives. Asian Affairs, 50(3), 323-343. https://doi.org/10.1080/03068374.2019.1636512

Tight, M. (2021). Globalization and internationalization as frameworks for higher education research. Research Papers in Education, 36(1), 52-74. https://doi.org/10.1080/02671522.2019.1633560

Utsumi, T. (2006). Global university system for engineering education in the age of globalization. European Journal of Engineering Education, 31(3), 339348. https://doi.org/10.1080/03043790600644081

Valenzuela, M. A., \& Rogers, S. E. (2018). Strategizing personality traits: an acculturation approach to person-environment fit and expatriate adjustment. International Journal of Human Resource Management, O(0), 1-29. https://doi.org/10.1080/09585192.2018.1526201

Watson, K. (2001). The Impact of Globalization on Educational Reform and Language Policy: Some Comparative Insights from Transitional Societies. Asia Pacific Journal of Education, 21(2), 1-18. https://doi.org/10.1080/02188791.2001.10600191

Weldon, P. A., Rexhepi, J., Chang, C. W., Jones, L., Layton, L. A., Liu, A., Mckibben, S., Misiaszek, G., Olmos, L., Quon, A., \& Torres, C. A. (2011). Globalization and higher education in Southern California: Views from the professoriate. Compare, 41(1), 5-24. https://doi.org/10.1080/03057925.2010.532360

Zhang, Q., Liu, R., Diggs, L. A., Wang, Y., \& Ling, L. (2019). Does acculturation affect the dietary intakes and body weight status of children of immigrants in 
the U.S. and other developed countries? A systematic review. Ethnicity and Health, 24(1), 73-93. https://doi.org/10.1080/13557858.2017.1315365 